\title{
The Laser Teaching Center at Stony Brook University
}

\author{
John Noé
}

John W. Noé, "The Laser Teaching Center at Stony Brook University," Proc. SPIE 9665, Tenth International Topical Meeting on Education and Training in Optics and Photonics, 966517 (3 June 2007); doi: 10.1117/12.2207519

SPIE Event: Tenth International Topical Meeting on Education and Training in Optics and Photonics, 2007, Ottawa, Ontario, Canada 


\title{
The Laser Teaching Center at Stony Brook University
}

\author{
John W. Noé \\ Department of Physics and Astronomy, Stony Brook University, Stony Brook, NY 11794-3800 USA \\ Phone: (631) 632-4303, Fax: (631) 632-8176, Email: John.Noe@stonybrook.edu
}

\begin{abstract}
The Laser Teaching Center is a unique university-based educational environment primarily devoted to highly personalized active learning through the development of individual hands-on student projects broadly related to optics and lasers. The participants include local high school students and young undergraduates who are new to optics and research, and graduate students in an optics rotation course. We describe the history and facilities of the Center, its educational philosophy and methods, and the experience obtained in nine years of operation.
\end{abstract}

Keywords: optics education, active learning, project-based learning

\section{Introduction}

The education and training papers at ETOP conferences typically describe specific programs, courses, curricula or methods that involve or can potentially impact relatively large numbers of students, sometimes hundreds or even thousands [1]. This paper, in contrast, describes a very modest optics learning environment, the Laser Teaching Center (LTC) at Stony Brook University, that has no set curriculum and only a small number of participants (fewer than ten) at any one time. Nevertheless, for a significant number of our students the LTC environment provides an invaluable or even life-changing experience, which encourages them to pursue a long-term interest in or career related to optics. These students will be our future colleagues and will educate future generations of students. Others benefit in more subtle ways by acquiring an appreciation of optics or the process of science, learning that it's possible to learn for oneself outside a classroom, developing a hands-on skill, or just becoming a better writer.

The primary activity of the Laser Teaching Center can be described as project- or inquiry-based active learning ("learning by doing"). Even the youngest of our students have a chance to really do science for themselves, starting from scratch. This is an invaluable opportunity since, as one of them once said: "you can't learn to ride a bicycle by reading a book." An essential component of the project-based learning process is learning to write about and freely discuss one's experiences, questions and results in a variety of settings, and eventually, to teach others.

The current LTC participants are mostly high school students, college freshmen from a Women in Science and Engineering (WISE) program, other undergraduates, and graduate students in an optics rotation course. All collaborate one-on-one with the LTC director and other mentors to develop individual projects related to optics which are specific to their interests, experience and ability. The projects utilize simple materials and equipment but can be as open-ended and intellectually challenging as time, interest and ability allow. Secondary LTC activities include running a small-group program for WISE high school students, hosting tours, and developing and conducting demonstrations. All of the activities of the Center are documented on its web site [2], mostly through reports and research journals written by the students.

As Kenneth Brecher has pointed out at this conference: "hands-on ... learning can offer students a unique opportunity ... [but such] learning from direct experience can be time consuming and expensive." [3] We certainly agree, and for this reason our personalized in-depth approach to optics education is not likely to be duplicated. The intent of this paper is not to offer a recipe or program to follow but rather to simply give a full description of an unusual educational experiment that naturally incorporates many proven pedagogies, such as learning-to-learn and writing-to-learn. Hopefully some of our ideas or methods will be of interest or prove useful to others.

Section 2 of this paper describes the background and early history of the LTC. Sections 3 and 4 describe the physical layout of the LTC laboratory and its equipment and resources, including the Linux and other computers that have an important educational role. The remainder of the paper summarizes the current activities of the Center (Sect. 5), its educational philosophy and pedagogy (Sect. 6), and results and recognition obtained (Sect. 7).

Tenth International Topical Meeting on Education and Training in Optics and Photonics, edited by Marc Nantel, Proc. of SPIE Vol. 9665, 966517 - (C) 2007 SPIE, OSA, IEEE, ICO doi: $10.1117 / 12.2207519$ 


\section{Background and Early History}

Stony Brook University (SBU) is located on the north shore of Long Island, $100 \mathrm{~km}$ east of New York City [4]. Founded 50 years ago, it is now the leading research campus of the State University of New York (SUNY) system with almost 24,000 students, about two-thirds of whom are undergraduates. The program for the approximately 80 undergraduate physics majors includes an optics concentration and an advanced course in laser physics. Current optics-related research in the department involves primarily laser-atom interactions and ultracold atoms, coherent control of molecular processes with ultrafast lasers, and x-ray optics. There is unrelated applied optics research on campus in the department of electrical and computer engineering. There is a growing number of optics-related companies in the area, but the density of these is nowhere near that in the well-known optics clusters in the US.

In the following, we describe how the Laser Teaching Center originated from student projects carried out in the 1990's in the research laboratories of Prof. Harold Metcalf, a pioneer of laser cooling of atoms and related topics. Since 1999 the Center has had its own dedicated laboratory in the SBU physics building and a full-time director.

Harold Metcalf was named a Distinguished Teaching Professor of Physics in 1999, in recognition of his widelyrecognized ability as a teacher and his many education-related initiatives over the previous three decades at Stony Brook. He was the first member of the department to be so recognized. In addition to the LTC, Metcalf established the Symposium on Undergraduate Research in 2001. The seven Symposia to date have provided nearly two hundred undergraduates a chance to present their optics-related research at the annual Frontiers in Optics joint meeting of the Optical Society of America (OSA) and the Division of Laser Science (DLS) of the American Physical Society [5].

Starting about 1980 Prof. Metcalf welcomed high school students (age 16-18) into his research laboratory each summer. They carried out small projects in a lively environment surrounded by graduate students, postdoctoral fellows and visitors. Initially these projects were connected in some way with the on-going research on diode lasers and laser cooling. Students could receive financial support through the Simons Summer Research Fellowship [6] established in 1984 by James Simons, the former head of the Stony Brook mathematics department and the founder of Renaissance Technologies Corporation, an investment company located close to the university. By the early 1990's there were about two students each summer, many of whom were Simons Fellows. Most of the students came from nearby Ward Melville High School or other local high schools relatively close to the university.

By the mid 1990's the student projects involved significantly more high school students from a wider range of schools as well as undergraduates supported by National Science Foundation (NSF) summer research fellowships and university grants. Also around 1995 the range of topics considered in the student projects began to take on a life of its own, inspired in part by exciting new developments related to optics. Single bubble sonoluminescence, first observed in 1989, was popularized by articles in the February 1995 issue of Scientific America magazine [7,8]. The simple setup described [8] was duplicated and has been used for some ten separate projects of varying complexity to date. Single beam optical tweezers, first reported in 1986 [9], was another focal point of student research at that time that continues to be of great interest.

A common feature of the student projects in the 1990's was the creation of printed reports. High school students often submitted reports to national science competitions such as the Intel Science Talent Search (Westinghouse STS prior to 1988). More advanced students, such as exchange students and visitors from European universities, typically prepared their reports in LaTeX. The library of these reports became an important legacy for future students.

Prof. Metcalf soon recognized the need for a permanent home for this sort of student research activity and sought funds to convert open corridor space in the basement of the physics building into a dedicated teaching laboratory. It took several years of effort to reach this goal, but funds for the renovations were eventually obtained from several private (non-government) sources. The donors included companies in local optics-related industries, who recognized the importance of such a facility for nurturing their future optics work force. One such company donated surplus lab benches and work tables to equip the new laboratory. The new permanent facility was dedicated October 1998 in a small "ground-breaking" ceremony at the hallway site. Participants included department and university officials, James Simons, and William D. Phillips, who shared the 1997 Nobel Prize in physics for his work with Metcalf on the laser cooling of atoms. 
It was apparent that the new facility would need a full-time manager to be a success. Metcalf was able to convince the department and university to support a dedicated executive director, who would develop and run the facility as well as be the primary teacher/mentor. The author, a tenured staff member in the department with a background in nuclear and accelerator physics, enthusiastically accepted the position when it was offered. One of the new director's first tasks was to come up with an appropriate name for the new facility, which had been referred to by a variety of generic terms such as "optical sciences lab" since its inception. The choice Laser Teaching Center was meant to convey a sense of excitement about optics research, and be appealing to young people. It was also sufficiently unique so as not to be confused with the many other optics-related Centers. A logo and distinctive signs and banners that incorporated the Laser Teaching Center name soon followed.

Early 1999 was a period of intense activity as the new laboratory was planned and set up. Considerable thought went into how the renovated space would be utilized, and the decisions made then have generally proven to be quite sound. The first summer program commenced that June with five high school and two undergraduate students carrying out projects in the new space. The most advanced project was by a 17-year-old high school student, Tina Shih, on a topic in non-linear optics (second harmonic generation in PPLN) [10]. It was later recognized through numerous awards.

The 1999 students shared a modest Linux computer with the apt node name "laser.physics." It hosted the LTC's web page and was used to prepare reports in LaTeX. In June 2000 "laser" was upgraded to its present form and a small network of three Linux-based terminals set up. Students working from these terminals created individual web pages, writing hand-coded html with a text editor. By the following summer (2001) the student web pages included lengthy research journals and detailed reports illustrated with graphs, drawings and pictures.

Fall 2000 marked the start of an important expansion of the Center's activities through a continuing partnership with the Stony Brook Women in Science and Engineering (WISE) program, which has both a high school and a college component [11]. One year earlier the LTC supported the first of many graduate student projects through the department's Optics Rotation course, whose participants carry out half-semester-long studies with their choice of several possible mentors. These academic-year activities have significantly broadened the scope of the LTC past the original concept of a facility for summer projects by high school students.

\section{Laboratory Layout}

The LTC is located in several connected rooms with a total area of about $100 \mathrm{~m}^{2}$. Its basement location is ideal, as it is both favorable for optics experiments (dark and quiet) and very close to optics research labs and the AMO (atomic, molecular, and optical) physics conference room. The main entrance door to the laboratory is at the foot of a prominent staircase leading down from the physics building lobby and the departmental office. A large colorful sign over the door announces "Welcome to the Laser Center" and displays our "laser-splash" logo. A small alcove next to the laboratory entrance has a whiteboard and chairs, and adjacent hallways have numerous showcases that display student posters and demonstrations. The focal point of this basement lobby area is an attractive display of the eleven Century of Physics Timeline posters from the American Physical Society [12], which was set up by the LTC in summer 2001. The final poster in this series features promising young scientists of the time, illustrated with pictures of some of the 40 finalists at the 1997 Westinghouse Science Talent Search competition in Washington, DC. One of these finalists was Long Cai from Ward Melville High School, whose project on x-ray focusing with Fresnel zone plates was one of those carried out in the Metcalf labs before the opening of the Laser Teaching Center.

The irregular floor plan of the laboratory (see figure, next page) was dictated by the shape of the hallway space available for the renovation. There is one relatively large room $\left(26 \mathrm{~m}^{2}\right)$ and one quite small one $\left(10 \mathrm{~m}^{2}\right)$ that can be isolated with doors, but the remainder of the space is open. Simple (bathroom-shower) curtains were installed in two doorways to isolate otherwise connected areas. The furnishing of the lab was dictated in a similar way by the pieces that had been donated or were otherwise available surplus on campus. (Only the large tool chest and a few plastic shelving units were purchased.) The high-quality $5 \times 8$ foot optical table is a key piece that is used for many small projects and demonstrations. 


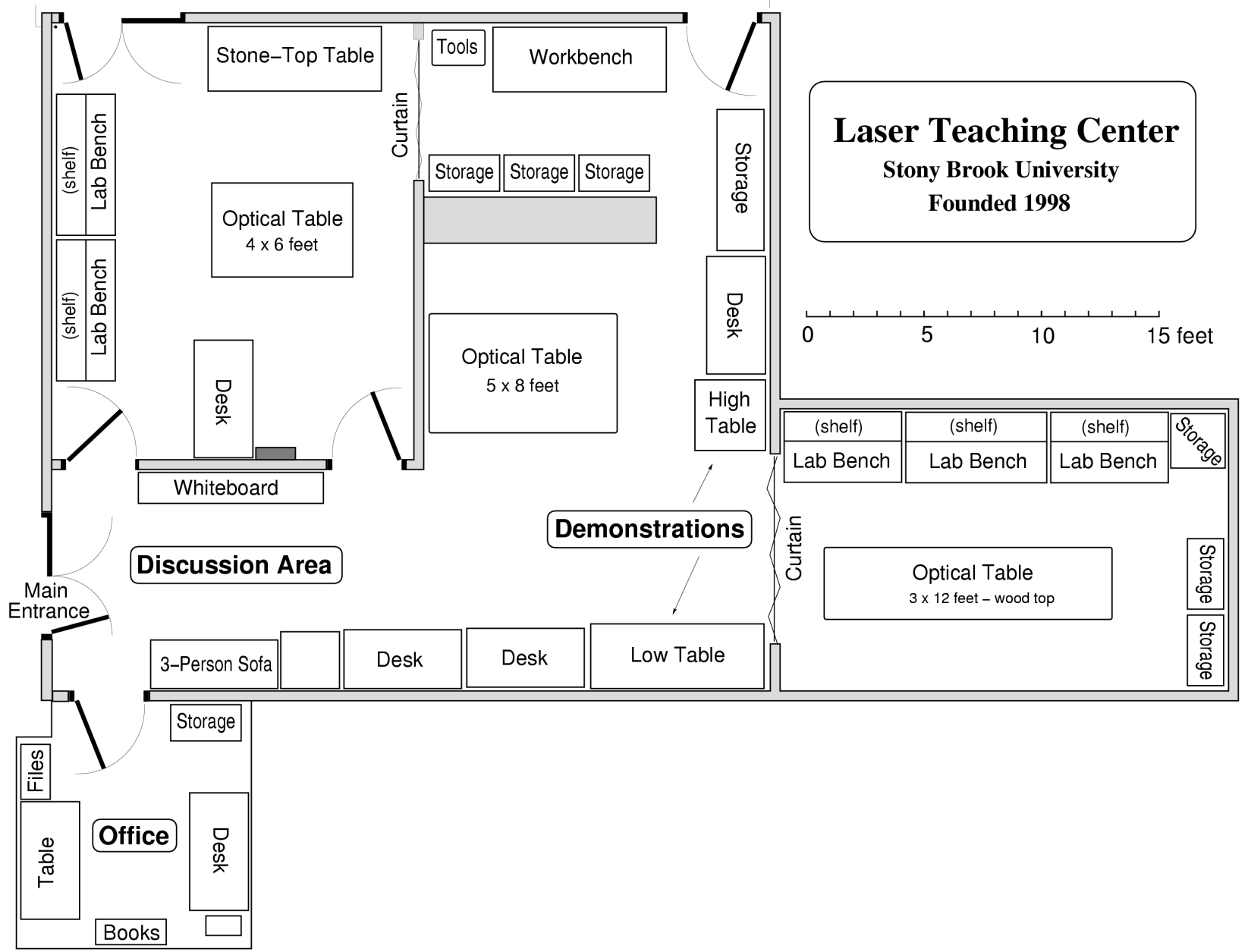

In retrospect, a very important 1999 decision was to create a discussion area just inside the main entrance door, with a whiteboard and facing sofa at a very comfortable distance (see figure). Much of the learning in the laboratory happens at this whiteboard. Shelves under it hold a variety of optics-related journals and magazines, which students are encouraged to explore. The small table next to the sofa has drawers with various supplies and demonstration items, and the "Mirage" toy [13] sits on top, prominently displayed. A bulletin board above the sofa is framed in decorative lights and covered with photos, project figures, and other memorabilia. Above this is a copy of the large LTC Welcome sign that that appears over the entrance door. This cozy area has turned out to be an excellent setting for quiet study, one-on-one discussions, or (with a few added chairs) working with small groups of students.

Another important laboratory space is the small office used by the LTC director. It contains the "laser" computer, a workgroup printer, a large reference library of optics books, and various files and special materials. A side chair at the desk welcomes students and visitors for conversations or shared internet research. The optics books are available to all, but can't be removed from the lab.

In the central area of the lab, several desks hold the computer stations that students utilize for their writing and internet research, and two tables hold a variety of additional demonstrations such as fish-tank optics, and polarized light effects. This area can accommodate groups of up to about fifteen standing students on tours. Elsewhere in the laboratory the closed room with the $4 \times 6$ foot optical table has been primarily used for longer-term experiments, including sonoluminescence, optical tweezers and $\mathrm{Rb}$ spectroscopy. The entire laboratory is decorated with posters somehow related to optics, including a number from past student projects. There are also two more large $(2 \times 8$ foot $)$ whiteboards (made from a cut $4 \times 8$ foot Melamine coated sheet) adjacent to the $5 \times 8$ and $3 \times 12$ foot optical tables. 


\section{Research Equipment}

Our research equipment has been intentionally kept very simple. This is in part to keep costs down but also for important pedagogical reasons. Most of the optics-related equipment has been donated or obtained surplus.

These items include:

- A variety of sealed HeNe lasers at 543 (green), 594 (yellow) and $633 \mathrm{~nm}$ (red), which deliver from under $1 \mathrm{~mW}$ to as much as $20 \mathrm{~mW}$, and matching power supplies. A larger HeNe (Spectra-Physics 127, $33 \mathrm{~mW}$ ) is on loan to us for an optical tweezers experiment, which also includes a donated 1970's vintage Nikon inverted microscope.

- An open-cavity HeNe laser $(633 \mathrm{~nm})$ based on a surplus Melles-Griot 05-LHB-570 tube. This is a very popular and useful tool for experimenting with laser modes. Learning to work with it can be very rewarding indeed.

- An $80 \mathrm{~mW}$ single-longitudinal-mode 532/1064 nm dual-wavelength laser (Lightwave 142-DW).

- Diode lasers at $780 \mathrm{~nm}(25 \mathrm{~mW})$ and $404 \mathrm{~nm}(5 \mathrm{~mW})$. The former have been used for optical tweezers and (with an external grating) rubidium spectroscopy.

- A fiber-optics breadboard with a small HeNe laser, two mirrors, and a fiber coupler. This setup provides an opportunity for new graduate students in particular to practice an important hands-on research skill, and it is also a useful source of spatially-filtered light for certain projects. Replacing the usual $633 \mathrm{~nm} H e N e$ with a $543 \mathrm{~nm}$ green HeNe allows interesting experiments with few-mode fibers.

- A basic computer-connected CCD camera (Electrim Model 1000N). This camera has been used in a number of experiments (including studies of imaging and the camera itself) and has been an important resource.

- A $1.2 \mathrm{~m}$ Gaertner slide, which has been used for projects on the Talbot effect and Fresnel zone plates.

- A large double-grating spectrometer (Optronic Labs, Model 740). Students have developed computer controls for this, enhancing its utility.

- Several silicon photodetectors (Thorlabs DET110) and a compact Hamamatsu photomultiplier for low-light measurements were purchased new. A donated linear-diode array has been useful for spectroscopy.

- Standard optical components such as mounts and rotators, polarizers and filters, lenses and mirrors. Some of the hardware items were donated, but most were purchased new from Thorlabs. We have found Surplus Shed [14] to be a convenient and inexpensive source for many optical elements.

Regarding electronic devices, most experiments require nothing more than a digital multimeter (DMM) for manually recording light level readings, but some projects utilize more advanced tools such as oscilloscopes, data acquisition devices, waveform generators, and sensitive amplifiers. Our oscilloscope is a $\$ 500$ surplus Tektronix 485 . Its bright analog display works well for demonstrating sound waveforms, and it is also fast enough to reveal $>500 \mathrm{MHz}$ beats between laser modes. Data acquisition can now be done with inexpensive USB-connected devices, but some past experiments have quite effectively used a Radio Shack DMM that writes one reading a second to a serial port.

A Sony Mavica camera (Model FD-73) that saves images on floppy disks has been very important tool for most of the history of the LTC. Although its $640 \times 480$ resolution is meager by current standards it is still quite appropriate for web-page images. The camera has an excellent lens with macro and 10x zoom capability. Students enjoy using it to document their projects, and some have carefully analyzed images to quantify a point-spread function or an interference pattern. Most of the thousands of pictures on the LTC web site were taken with this camera.

Computer technology is also intentionally kept simple, in large part for pedagogical reasons. There are currently four platforms in active use: DOS, Microsoft Windows 95, Microsoft Windows XP, and Linux.

- Our legacy DOS computer supports the 1980's era Quattro-Pro spreadsheet program, which has proven to be a very effective instructional tool for plotting, data analysis and simple numerical simulations. QPRO produces attractive .eps plots with little effort, and most of the plots on student web pages have been done with it.

- Our Windows 95 desktop computer on a roll-around cart also supports just one application: the legacy Electrim CCD camera described above and Scion Image software. It can be connected to the network for file transfers. 
- Our Windows XP desktop computer supports a wider, and growing, variety of student research and instructional needs. PowerPoint is used for presentations, by high school WISE program students in particular. Mathematica, available at no cost under a campus license, is excellent for creating interactive simulations. BEAM2 [15] is a very affordable and useful tool for ray tracing studies, as described in a separate paper at this conference [16].

- Our Linux server "laser" and the thin-client terminals mentioned in Sect. 2 continue to be the heart of our system and are of great importance for learning. It is impressive that young high school and undergraduate students with no significant prior computer experience can adapt so easily to writing html code in a text editor like pico or emacs, once they learn a few basic Linux commands and experience the reward of creating a visually attractive and informative web journal or report. It is common for students to log in to "laser" from their home or dorm room to continue their work. Our X-windows environment is a very basic version of FVWM, and there is no graphical "desktop." Especially useful applications include xfig for creating vector graphics, $\mathrm{xv}$ and ImageMagick for image processing, and gnuplot for plotting. It is testimony to the efficiency of Linux that a modest PC with a 4 GB hard drive can support several users at once and almost 150 user accounts (web pages).

The trend for the future is for our eclectic computing environment to become ever more diverse. Today's students often bring their own laptops to the lab, and access their accounts and web pages on the Linux server through the network. Students have also begun to prepare LaTeX reports directly on their laptops, using easily-installed opensource software. More and more laptops run Apple OS-X or Linux. Another trend is that research tools such as cameras, data acquisition devices and compact spectrometers are increasingly interfaced through USB connections, and computers linked to wireless networks. We plan to respond by purchasing one or more modest laptop computers that can easily be moved around the lab, while remaining connected to the central "laser" computer.

\section{The LTC Programs}

The primary activity of the Laser Teaching Center is the collaborative development of individual projects. The student collaborators come from a variety of sources, and in some cases are carefully selected from a pool of applicants. The types of projects also vary, and depend in part on the time available and the student's background. The busiest period of the year is summer, roughly mid-June to mid-August, when a total of about eight high school and undergraduate students work together full-time. The summer program includes weekly lunch seminars by guest speakers and optics classes prepared by the undergraduates. Another hectic period is fall, when high school students work holidays, evenings and weekends with the director to complete and write papers on projects for the national science competitions. The focus of the spring semester is the more even-paced college WISE course (see below).

The main secondary activity of the Center is an academic year program for small groups of high school junior girls in a separate WISE program. They spend an afternoon about once a month in the laboratory seeing demonstrations, learning basic optics, and doing group activities such as focusing sunlight, comparing waveforms of musical instruments, or measuring hair sizes by diffraction. They may develop a group presentation, but do not work individually. These activities are well documented on the LTC web site with numerous pictures. Other secondary LTC activities include giving lab tours, often with optics demonstrations, and some outreach and recruiting.

Most of the individual projects carried out fall into one of the following three categories:

1. Fairly standard tutorial exercises that acquaint a student with a topic, technique, or field of optics. These can be similar to the experiments "performed" in regular teaching laboratories, with the key difference that our students spend much more time, several weeks or even a full semester. There are no written instructions, although sometimes a published article or a previous student's report is a guide. The topic studied is typically suggested by the mentor as something related to the student's specific interests, once these have been determined through conversations. The final product could be a web-page report, a poster, an oral presentation, or some combination of these. Past project topics have included: Fourier optics, microwave Bragg scattering, laser beam propagation and focusing, elliptically-polarized light, interferometry, fiber optics, and photo-refractive optics. The set-ups for most of these projects are created from scratch by the students.

2. Experiments related in some way to relatively advanced topics of current research interest. Many high school students write 20-page reports for science research competitions, and some research has been presented at optics meetings such as OSA/DLS and DAMOP. Topics of particular interest include: optical vortices and singular optics, optical tweezers, and acousto-optics. Although the topics are advanced the actual project need not be 
complex. One high school student studied vortex-phenomena in flowing soap films with a very simple apparatus [17]. This project was recognized as one of the top 40 in the nation in the 2003 Intel competition.

3. Projects that are simple yet creative explorations or demonstrations of everyday devices or phenomena related to light, optics, or sound, as described further in a separate paper [18]. Often the topic is suggested by something the student is just curious about or wants to "invent," or by a chance observation or news article. These projects are typically summarized in web-page reports that may include numerous pictures and hand-drawn diagrams.

All of our students are given the opportunity and challenge to suggest any feasible project they wish. Those new to research soon learn that finding a suitable project topic is itself a research problem, a valuable lesson. A few have a good idea almost immediately, others may come up with one on their own after a few weeks, but the majority of students require some sort of guidance. We often hear "I give up, tell me what my project is!" and respond "let's see what we can come up with together." Such projects are typically modest in scope initially but can be very openended. Graduate students typically prefer to base a project on a specific suggestion or published article.

The LTC student community has several components:

- High school students (age 16-18). Many of these students have been accepted into the Simons summer research program [6] and are looking for a research opportunity related to optics; others contact us directly. All of our final candidates come in for lengthy interviews. A peculiarity of high school education on Long Island is that a significant and growing number of schools support in-school "science research" programs, often with a dedicated teacher. These programs present research as a methodology and emphasize achieving success in organized science competitions. In our interviews we look for students who can demonstrate a working knowledge of subjects they've "taken" in school, and who are motivated primarily by natural curiosity. A few high school students are accepted in their sophomore year, and thus have a possibility for an extended experience over two summers and (if they are within commuting distance) the intervening year. Our high school students who live relatively close by often take Stony Brook college courses through the Young Scholars program [19].

- WISE program freshmen (age 18 or 19). The Women in Science and Engineering (WISE) program includes an Introduction to Research course (WSE187) in the spring semester of freshman year. We have taught a section of this class since 2001, with typically 4-6 students. The course is normally arranged as a three-cycle rotation, but our students can elect to stay for the entire semester, and most do. We encourage all potential physics and astronomy majors to participate. These young women have generally turned out to be excellent LTC students, very receptive to learning and appreciative of this opportunity. Several past students are now committed to careers in physics or astronomy research or teaching; one of these is now a graduate student of quantum optics.

- Other Stony Brook undergraduates. The Center is open to any undergraduate in our department with an interest in optics. They can enroll for course credit, or not. Some students continue work started in the WSE187 course.

- Summer undergraduates. These students have received an NSF-REU fellowship to a 7-week summer research program. We review the applications and select a few of the admitted students with a strong interest in optics but as yet limited experience, who would be willing to work with high school students. Some past REU Fellows have been from Stony Brook, including three young women who had just completed the freshman WISE course.

- Graduate students in an Optics Rotation course. Optics Rotation (OR) gives new physics graduate students an exposure to optics research in the department. Students carry out two projects a semester with a mentor of their choice; some enroll for two semesters. Enrollments fluctuate, and we have had as many as nine OR students in one calendar year. Many are quite experienced already, but for others this is their first opportunity for significant hands-on work. The OR students tend to work (or want to work) very independently, rather than collaboratively.

- High school teachers. There is just one example to date, a physics teacher in training who collaborated on a project about soap film colors in spring 2004 [20]. It was rewarding experience for both student and mentor, and we look forward to having more such highly-motivated adult students in the future.

While the primary LTC mentor is its full-time director, there is a growing community of other mentors. These include Marty Cohen, a retired optical physicist, and Anand Sivaramakrishnan, a Stony Brook adjunct professor of astronomy. Their specialized expertise has been invaluable for projects related to acousto-optics and wavefront sensing respectively. Regular summer visitors include Kiko Galvez of Colgate University and Sam Goldwasser, creator of "Sam's Laser FAQ." Graduate and undergraduate students also serve as mentors and laboratory assistants. 


\section{Educational philosophy and pedagogy}

We are not professional educators [21]. We have been guided solely by instinct and intuition, and personal experience with the power of engaged active learning. The proven Suzuki method of violin instruction and the more recent One Laptop Per Child (OLPC) initiative [22] are based on the premise that young children, given appropriate tools and placed in a supportive environment, have an unlimited potential to learn. We seek to create a similarly supportive environment for a wider range of students in the context of optics. It is widely recognized that optics is an ideal vehicle for teaching more general lessons about science and research, for a variety of excellent reasons. But we must not forget that we are educating students using optics, not just teaching about optics. We are not trying to develop or transmit any particular skills (train), but rather nurture a state of informed curiosity that makes selfdirected learning possible. We want our students to "learn how to learn" for themselves. Mark P. Silverman has written extensively and eloquently about self-directed learning, which he terms a "heretical experiment" [23,24]. Our educational philosophy has much in common with Silverman's ideas and is no less heretical.

Writing is a very important part of our pedagogy. Every student receives a bound notebook, and is encouraged to use it well and often; some eventually need more than one. Notebooks complement keyboard writing by encouraging drawing and visual thinking. The internet journals that students create often express the excitement and frustration of research in refreshingly honest and original terms. We encourage them to also write "Answers and Questions." Answers are just things that are now personally understood, facts or observations; Questions are things that one doesn't understand or are just curious about. Questions are for the future and may never have a matching Answer [25]. Writing more formal reports well is often a challenge that can only be met by writing collaboratively with a mentor, and we often provide students with their first such experience. We insist on precise language, and a logical and consistent technical style. Sometimes getting a few sentences right can take hours! Through such carefully crafted writing, eventually students come to appreciate how every word and phrase is important in a scientific paper. Writing web pages in hand-coded html, and printed reports in LaTeX, develops computer literacy and with this a further appreciation of precise syntax and logical structure in writing. Writing emails well is important too; without this there can't be meaningful collaboration with mentors at a distance, or letters addressed to relevant scientists.

Even more important than writing is speaking, trying to communicate or explain something extemporaneously to another person while on one's feet. Our students get lots of practice at this in all sorts of contexts. Prepared talks are valuable too, but not as much so. Realizing that one doesn't really understand something when one goes to explain it is a powerful motivator! In short, this Yogi tea tag has it right - "To learn, read. To know, write. To master, teach." Our approach to mentoring has been called "getting into kids' heads" by someone who knows the author well. Getting into kids' heads means asking questions about students' interests, gauging their reactions to new ideas and experiences, sensing their concerns, and just generally customizing the interaction. This type of mentoring is about far more than giving advice, or even knowing when NOT to give advice. It involves building a personal relationship based on trust, which can only be developed over a period of time from shared experiences and challenges. (Sharing disappointments and misunderstandings is even better.) Students will only absorb and accept advice if they feel comfortable discussing and even disagreeing with it. It's far better in the long run for the student to have the mentor say "I don't know. / I'm confused. / Let's figure it out. / You tell me." than to be just "given the answer." Especially during the busy summer program there is also peer mentoring, where students from disparate backgrounds learn from each other and thereby gain a further appreciation of the importance of collaboration.

The term holistic learning is used in a variety of ways, for example to describe learning that involves feeling, imagination, thinking, and acting. We think of it as simply meaning educating the whole person, or educating by involving the whole person. In the lab the optical table is steps from the whiteboard and sofa (for discussions and just pondering), the computer terminals (for writing), and the reference library. A student can move without hesitation from handling an optical element or seeing a curious effect to making a drawing on the board, or delving into a book. It is a fertile setting for learning that engages equally well the mind, the imagination and the senses.

In contrast to currently popular trends, with beginning students we minimize the use of technology, both computer and optics-related, and improvise whenever possible. It is far preferable initially to record a few hundred data points by hand and carefully match them (by manually altering parameters) to a theoretical function in a simple spreadsheet than to see a result pop up on the screen with no effort. One beauty of optics is that with a few simple tools one can get data (the intensity profile of a laser beam, for example) that match a theory astoundingly well. 
These and other lessons that we hope our students will absorb can be summarized as follows:

- Knowledge has endless layers of complexity that are revealed through inquiry and research.

- Real science can be exciting and fun, but it requires much hard work and is often frustrating.

- Don't accept "black boxes" - strive to "look under the hood" to learn how things work.

- Scientists are real people, and most often very willing to help an informed student.

- Collaboration enriches, but honest competition is valuable too.

- Humility and thoughtful curiosity are essential states of mind.

\section{Results and recognition}

We can only meaningfully evaluate the lasting impact of what we do on a person-by-person basis, over a time frame even longer than the nine-year lifetime of the Center. It is hard to judge the long-term impact of any educational experience, but for a significant number of our students their LTC experience has clearly been a very important or decisive influence that opened the door to further opportunities and/or stimulated a continuing interest in research, physics or optics. (The defining moment could be achieving success in a challenging project, or maybe just a brief conversation with a famous scientist.) As mentioned in the introduction, many others have benefited in a variety of more subtle ways that are hard to assess.

We can, however, make two general observations about outcomes based on specific student experiences:

- A significant fraction of our former undergraduates, from both Stony Brook and elsewhere, and even some of our earliest high school students, are now in optics-related $\mathrm{PhD}$ programs at prestigious universities (three are at Harvard alone). In several cases there is a clear connection between the early interest nurtured through the LTC student project and the eventual research specialty. For numerous others among our still-current undergrads and former high school students, such an academic career path is a strong possibility.

- Several of our Stony Brook undergraduate students have gone directly to work in a local laser company. It will not surprise the ETOP community that there is a large and growing demand for employees with some optics experience who can "think on their feet and work with their hands." The new optics specialization in the undergraduate physics program will hopefully help create a pathway to the local optics industry for others.

Visitors to the Center, especially those who meet our students, have invariably been impressed. Our distinguished visitors include former OSA head Anthony Johnson, Professor Sir Michael Berry, and 1997 Nobel Laureates William Phillips and Claude Cohen-Tannoudji. The LTC has been featured in various campus publications and cited in Physics Today [26]. Our high school students have been recognized by numerous awards in national and international competitions, and several of our former undergraduate students have received prestigious fellowships for graduate study. Significantly, much recognition has also come from our students, who frequently express their appreciation of the LTC experience in notes, emails and web journal comments.

\section{Conclusions}

Some of the conclusions we can reach from nine years experience with this unusual experiment in optics education may seem obvious. First and foremost is that the most enduring teaching and learning takes much time and patience, and a relaxed trusting relationship between mentor and student. A corollary is that it's quite possible to "do a lot with a little" and this may well teach more than using expensive equipment that's not well understood. Writing is clearly important, and giving students a way to write for the web is empowering. Letting students teach others and make mistakes is even more so. Finally, every student is different and has to be related to in a unique way. Personalized learning is indeed time consuming and often frustrating, but it opens doors to unbounded growth and success.

An important question for the future is how to sustain and further develop such a labor-intensive undertaking, while maximizing its effectiveness. One possibility is to offer the LTC experience to more high school teachers, who could in time assume a leadership role in training further teachers, as well as their students, in our approach. 


\section{Acknowledgments}

The author is indebted to Harold Metcalf and the Department of Physics and Astronomy at Stony Brook University for providing the opportunity to develop and direct the Laser Teaching Center over the last nine years. Hal has been an inspiring person to work with, and I have learned much about both optics and education from him.

I would also like to thank the many friends and colleagues who have contributed to the success of the Laser Teaching Center, including mentors Marty Cohen, Kiko Galvez, Sam Goldwasser and Anand Sivaramakrishnan, Rich Migliaccio of East Coast Optical Technologies, and Robert Segnini of the Department of Physics.

The interest and support of Carrie-Ann Miller, Sharon Pavulan, Amy Rosen, and Lauren Macri from the WISE program is greatly appreciated. The network of Linux computers that has been so essential to the laboratory was developed by Daniel Noé. The assistance, advice and encouragement of Azure Hansen have also been invaluable.

The Center was created and furnished with contribution from numerous sources including Symbol Technologies, the Swartz Foundation, the Simons Foundation, Olympus America, and Northrop-Grumman. Numerous small companies have contributed since, including Vere, Sydor Optics and Duke Scientific.

Last but not least, I would like to thank our many enthusiastic and hard-working students, without whom the LTC would not have been possible.

\section{References}

[1] ETOP (Education and Training in Optics and Photonics) conference proceedings are freely available at http://spie.org/etop/.

[2] Stony Brook Laser Teaching Center website, http://laser.physics.sunysb.edu/.

[3] Kenneth Brecher, "Project LITE: Light Inquiry through Experiments," ETOP-2007, Ottawa (this conference).

[4] Stony Brook University, formerly known as the State University of New York (SUNY) at Stony Brook, http://stonybrook.edu/.

[5] Symposium on Undergraduate Research, http://laser.physics.sunysb.edu/research-symposium/.

[6] Simons Summer Research Program, Stony Brook University, http://stonybrook.edu/simons/.

[7] Seth J. Putterman, "Sonoluminescence: Sound into Light,” Scientific American, February, 1995.

[8] Robert Hiller and Bradley Barber, "Producing Light from a Bubble of Air," Scientific American, February, 1995.

[9] A. Ashkin, J.M. Dziedzic, J.E. Bjorkholm and S. Chu, Optics Letters 11, 288-290 (1986).

[10] Tina Shih, Laser Teaching Center, summer 1999, http://laser.physics.sunysb.edu/ tina/.

[11] Women in Science and Engineering (WISE) program, Stony Brook University, http://www.wise.sunysb.edu/.

[12] A Century of Physics Timeline. American Physical Society, March 1999, http://timeline.aps.org/.

[13] “Mirage," Opti-Gone International, Ojai, California, http://optigone.com/.

[14] Surplus Shed, Fleetwood, PA 19522 USA, http://www.surplusshed.com/.

[15] BEAM2 ray-trace software. Stellar Software, Berkeley, California, http://www.stellarsoftware.com/.

[16] Sriya Adhya and John Noé, “A Complete Ray-trace Analysis of the Mirage Toy,” ETOP-2007, Ottawa (this conference).

[17] Hilary Fleischer, Laser Teaching Center, summer 2002, http://laser.physics.sunysb.edu/ hilary/.

[18] John Noé, “Simple Creative Projects from an Optics Teaching Laboratory,” ETOP-2007, Ottawa (this conference).

[19] Young Scholars Program, Stony Brook University, http://www.stonybrook.edu/ugadmissions/programs/youngscholars.shtml/.

[20] Eric Tompkins, Laser Teaching Center, spring 2004, http://laser.physics.sunysb.edu/ ett/.

[21] By "we" here I mean to include Harold Metcalf. Our ideas and instincts in these matters are remarkably aligned.

[22] One Laptop Per Child project (OLPC), http://laptop.org/.

[23] Mark P. Silverman, "Self-directed learning: A heretical experiment in teaching physics,” Amer. J. Physics 63, 495 (1995).

[24] Mark P. Silverman, "Self-directed learning: Philosophy and implementation." Science \& Education 5, 357-380 (1996).

[25] Newton's scientific notebooks are a great example of this style of inquiry and more. Read them at http://www.newtonproject.sussex.ac.uk/.

[26] Kate Kirby, Roman Czujko, and Patrick Mulvey, “The Physics Job Market: From Bear to Bull in a Decade,” Physics Today, April 2001, http://aip.org/pt/vol-54/iss-4/p36.html/. 